\title{
Acid maltase deficiency: treatment of respiratory insufficiency with cuirass respirator
}

\author{
A. E. J. de Jager ${ }^{1}$ and A. F. Meinesz ${ }^{2}$ \\ ${ }^{1,2}$ Respiratory Intensive Care Unit, \\ ${ }^{1}$ Department of Neurology and ${ }^{2}$ Department of Pulmonary Medicine, University Hospital, \\ Groningen, The Netherlands
}

\begin{abstract}
Summary. Three patients with the late-onset form of acid maltase deficiency showed a gradual weakening of proximal limb and trunk muscles leading to severe respiratory insufficiency. Considerable deterioration of pulmonary function occurred owing to a vicious cycle of hypoventilation and exhaustion. Treatment by nocturnal cuirass ventilation with tailor-made shells was successful. The muscle weakness still progressed very slowly but there were no more respiratory problems.
\end{abstract}

Key words: Acid maltase deficiency (late-onset form) - Respiratory insufficiency - Cuirass respirator

Zusammenfassung. Drei Patienten mit dem Saure-Maltase-Mangel-Syndrom im Erwachsenenalter sind beschrieben. Klinisch gab es eine langsam progrediente aszendierende Lähmung von Gliedgürtelmuskeln und Rumpfmuskeln. Schließlich entstand eine respiratorische Insuffizienz. An diesem Moment gab es schon eine erhebliche Störung von der Lungenfunktion durch ein Circulus vitiosus von Hypoventilation und Erschöpfung. Die Patienten wurden behandelt mittels nächtlicher Küraszventilation mit angepaßten Schalen. Diese Behandlung war erfolgreich. Die Muskelschwäche war noch langsam progredient, ansonsten gab es keine Atemprobleme mehr.

\section{Introduction}

The glycogen storage diseases or glycogenoses are divided into various subtypes. One of these is glycogenosis II (Pompe's disease), which is due to deficiency of the lysosomal enzyme acid maltase ( $\alpha-1,4$-glucosidase). Absence of this enzyme leads to accumulation of glycogen in the lysosomes and diffusely in the tissues. The clinical picture of Pompe's disease is variable and the disease may manifest itself at different ages in different clinical patterns [4]. In the so-called late-onset form, the presenting symptoms are always due to weakness of skeletal muscle. The muscles

Offprint requests to: Dr. A. E. J. de Jager, Department of Neurology, University Hospital, Postbus $30.001,9700 \mathrm{RB}$ Groningen (Netherlands) 
of the pelvic and shoulder girdles are especially affected, usually starting with the former. Later on, the muscles of the trunk and proximal limbs show weakness. There is considerable muscle wasting. The symptoms become evident in older age but in retrospect impairment in motor performance often has been present for years [6]. Most of the patients were bad at gymnastics in school. They had had a waddling gait for many years and complained of low back pain because of weakness of the back muscles. The disease is slowly progressive. Up to $50 \%$ of the patients finally develop respiratory failure which, without therapeutic intervention, leads to death $[3,5]$. In a few cases respiratory difficulties are the initial manifestation $[8,9]$. Various therapeutic methods have been tried. These range from ketogenic diets to attempts to replace the defective enzyme [3]. Sometimes temporary improvement is seen but none of these measures can bring the disease to a standstill. When the patients develop respiratory problems, some sort of artificial respiratory support becomes essential.

\section{Material and methods}

In the past 15 years three patients with the late-onset form of Pompe's disease in severe respiratory failure were admitted to our Respiratory Intensive Care Unit. Two of them had been in a similar condition shortly before, necessitating mechanical ventilation for some time. Then they were gradually weaned from the respirator. However, respiratory problems recurred. Therefore, some form of maintenance respiratory treatment became mandatory. We decided to use intermittent nightly artificial ventilation by way of a cuirass respirator. This apparatus consists of a shell and a ventilator which supplies intermittent positive and negative pressure to anterior and lateral chest wall and abdomen. The usual shells are manufactured for normal chest walls. However, in our patients the chest wall deformity caused by dystrophy of shoulder and chest muscles precluded the necessary proper fitting, thus causing air leakage between thoracic wall and shell. We therefore adapted the shells to the deformed chest in the same way as for kyphoscoliotic patients [10]. These tailor-made shells were made of polyester enforced with glass fibre and a foam-rubber ring. They were modelled from a plaster of Paris cast of the patient's thoracic cage. A Monaghan $170 \mathrm{C}$ cuirass respirator was used.

\section{Patient 1}

This man had developed normally, played soccer and made long cycling tours. In 1949 , at the age of 22 years, he noticed difficulty in running for the first time. In the next few years the problem increased and he started to walk with a swinging gait. Since 1953 he had complained of low back pain. On exertion, shortness of breath was noticed. In 1963 the patient was hospitalized six times in another hospital with a diagnosis of pneumonia; on those occasions extreme cyanosis was always noted. In 1964 he was referred to the Department of Neurology, Groningen, because of somnolence, headache, and papilloedema. At that time muscle weakness was noticed in the muscles of the shoulder and pelvic girdles. Vital capacity was 1.91 (predicted 5.51). Because of respiratory failure $\left(\mathrm{PaCO}_{2} 110 \mathrm{~mm} \mathrm{Hg}, \mathrm{SaO}_{2} 91 \%, \mathrm{pH} 7.15\right)$, mechanical ventilation was necessary for a short period. The next year he experienced three similar episodes, each time necessitating admission to the Respiratory Intensive Care Unit. At first he was thought to suffer from muscular dystrophy but later on a diagnosis was made on Pompe's disease by means of muscle biopsy. After the third admission the patient was considered to be a candidate for intermittent cuirass ventilation. He was treated with a cuirass respirator with a standard shell (tailor-made shells were not then available). Thereafter he felt much improved. He used his cuirass at night and for $1 \mathrm{~h}$ after lunch. In 1974, the shell was worn out and he obtained a new one. This standard shell did not fit very well because of the muscular wasting away in shoulders and thorax. A tailor-made shell was now constructed and applied with success. Socially the patient is 
doing well. After discharge from hospital in 1965 he got an administrative job, working in the morning at his office and in the afternoon at home. This has not changed during the past 17 years. Recent neurological examination showed severe weakness in shoulder, trunk and pelvic muscles. There was a nearly total paralysis of intercostal muscles and of the diaphragm, the patient breathing with his auxiliary respiratory muscles. Although he states that his strength has not decreased, in our opinion his motor power is a little less than some years ago. There is marked muscular dystrophy in pelvic, shoulder, trunk and intercostal muscles.

\section{Patient 2}

This man was in good health until 1968 when, at the age of 52 years, he started to complain of low back pain. In the following years he had difficulty in climbing stairs. According to his family his gait had been strange and unstable for a long time. Physical examination revealed weakness in the shoulder and pelvic muscles. In 1970 in another hospital a diagnosis of chronic polymyositis was made. Treatment with corticosteroids gave no improvement. In the following years the strength in his thighs gradually decreased. On exertion there was shortness of breath. At the age of 59 he was admitted in acute respiratory failure to our Respiratory Intensive Care Unit $\left(\mathrm{PaCO}_{2} 150 \mathrm{~mm} \mathrm{Hg}\right.$, $\mathrm{PaO}_{2} 46 \mathrm{~mm} \mathrm{Hg}$, pH 6.96 whilst receiving oxygen by nasal catheter). The vital capacity was $0.5 \mathrm{l}$, when his condition improved, it was 2.01 (predicted value 3.61 ). On physical examination marked weakness was found in the shoulder, pelvic, and trunk muscles. The deep tendon reflexes of the arms were normal and those of the legs, diminished. Respiratory excursions were small and the patient used his auxiliary respiratory muscles. Endotracheal intubation was carried out and his respiration was mechanically assisted. Routine examination of blood and urine was within normal limits with the exception of a slightly elevated serum creatine kinase. The EMG showed a myopathic pattern. A presumptive diagnosis of Pompe's disease was made. This was confirmed by biopsy: both muscle and cultured skin fibroblasts showed a decrease in acid maltase activity. At first the patient was mechanically ventilated via an endotracheal tube with a Servo ventilator. To avoid a tracheostomy, he was changed to a cuirass ventilator using a commercially available shell. After discharge, he used this cuirass only at night. Because the shell did not fit well there was continuous leakage of air leading to insufficient ventilation and persistence of his complaints. When after some months he obtained a tailor-made shell his complaints soon disappeared. Since that time he has remained well. He is now retired and spends his time gardening. He still uses the cuirass only at night. Recent neurological examination showed no changes in his muscle power with the exception of the pelvic muscles that seemed a little more affected than in 1975 . This patient and his family have been reported elsewhere [2].

\section{Patient 3}

A 35-year-old mechanic noticed loss of strength in his upper legs in the spring of 1977 . He was also restless, slept badly and felt overwrought. During the preceding 7 years he had been treated for low back pain. As a child he was clumsy and never performed well in gymnastics. When he became engaged at the age of 21 , his fiancée noticed that he had a peculiar way of walking. On examination in another hospital in 1977, weakness was observed in the muscles of the shoulders, trunk, and pelvic girdle. A diagnosis of muscular dystrophy was made. The patient became also dyspnoeic on exertion. In February 1978 he was hospitalized because of respiratory failure; mechanical ventilation by endotracheal intubation was required for 1 week. Thereafter his condition at first somewhat improved, but within 5 weeks again severe respiratory insufficiency developed. On admission to our Respiratory Intensive Care Unit he was very drowsy and dyspnoeic. Tachypnoea $(40 / \mathrm{min})$ and tachycardia $(132 / \mathrm{min})$ were present. Vital capacity was reduced to $1.2 \mathrm{I}$ (predicted value 5.6 l). $\mathrm{PaCO}_{2}$ was $115 \mathrm{~mm} \mathrm{Hg}, \mathrm{PaO}_{2} 100 \mathrm{~mm} \mathrm{Hg}$ and $\mathrm{pH} 7.22$ (during administration of oxygen). On examination, moderate weakness was seen in the shoulder and pectoral muscles. Respiratory excursions were small and coughing was inadequate. Trunk and pelvic muscles showed severe weakness. Marked muscular dystrophy was observed in the pelvic and shoulder girdle. The patient could not rise from a chair without help and he walked with a waddling gait. Lumbar lordosis and protrusion of the abdomen were present. Deep tendon reflexes were diminished in the arms and absent in the legs. Routine laboratory tests showed a 
slight increase in serum creatine kinase. The EMG had a myopathic pattern; pseudomyotonic volleys were noticed in the paraspinal muscles. On clinical grounds, a diagnosis of Pompe's disease was made. This was confirmed by enzyme studies in muscle and leucocytes. During the patient's stay in hospital, a tailor-made shell was constructed. He easily adapted to it and is now feeling well, using his cuirass only at night. There have been no changes in his motor power during the past 4 years. He has not yet returned to his former job, training for a new one, but has already resumed his hobby, local politics.

\section{Discussion}

Nearly half of the patients with the late-onset form of Pompe's disease show respiratory muscular involvement (diaphragms and intercostal), eventually leading to respiratory failure and, when untreated, to death. The decline of the disease in our patients was very slow until the moment of dyspnoea on exertion was reached. Thereafter, in a short time total respiratory insufficiency became manifest with severe $\mathrm{CO}_{2}$ retention. It is unlikely that the disease itself at that time showed such rapid deterioration. It is more likely that the development of a vicious circle of progressive hypoventilation with hypoxia and hypercapnia, giving way to feelings of discomfort and exhaustion, ultimately led to more hypoventilation. Undernourishment may also have played a role [1].

In patients with diaphragmatic dysfunction hypoventilation becomes especially prominent in the supine position. The dystrophic diaphragm then becomes more elevated and the effect of the auxiliary respiratory muscles is diminished. Chronic hypoventilation leads to the development of micro-atelectases, resulting in disturbances of the ventilation-perfusion ratio. Initially there is only hypoxaemia but soon hypercapnia develops with a compensatory respiratory acidosis. Minor intercurrent factors such as a viral upper respiratory tract infection may then suddenly provoke an acute deterioration. Endotracheal intubation and artificial ventilation are then necessary. After some time it is possible to change from continuous to intermittent ventilation. Mechanical ventilation not only improves the respiration but also removes the micro-atelectases, leading to a normalization of blood gases (Table 1 and Fig. 1). At the same time, the respirator takes over the function of the fatigued muscles so that these muscles may be restored to their maximum capacity. One of our patients started cuirass ventilation in 1965 .

\begin{tabular}{lccccc}
\hline & \multicolumn{1}{c}{$\mathrm{A}$} & & \multicolumn{1}{c}{$\mathrm{B}$} & \\
\cline { 2 - 3 } \cline { 5 - 6 } & - & + & & - & + \\
\hline $\mathrm{pH}$ & 7.32 & 7.43 & 7.47 & 7.45 \\
$\mathrm{pO}_{2} \mathrm{~mm} \mathrm{Hg}$ & 40 & 57 & 73 & 91 \\
$\mathrm{pCO}_{2} \mathrm{~mm} \mathrm{Hg}$ & 87.5 & 57 & & 37 & 41 \\
$\mathrm{O}_{2}$ sat. \% & 66.5 & 87.5 & 95 & 97.5 \\
\hline
\end{tabular}

Table 1. Effect of cuirass ventilation ${ }^{2}$ on patient 1

a $-=$ without cuirass; $+=$ with cuirass; $\mathrm{A}:$ when cuirass treatment was started; B: some years later when the patient was used to regularly intermittent cuirass ventilation. Without cuirass there was hypoxia but hypercapnia was not yet evident 

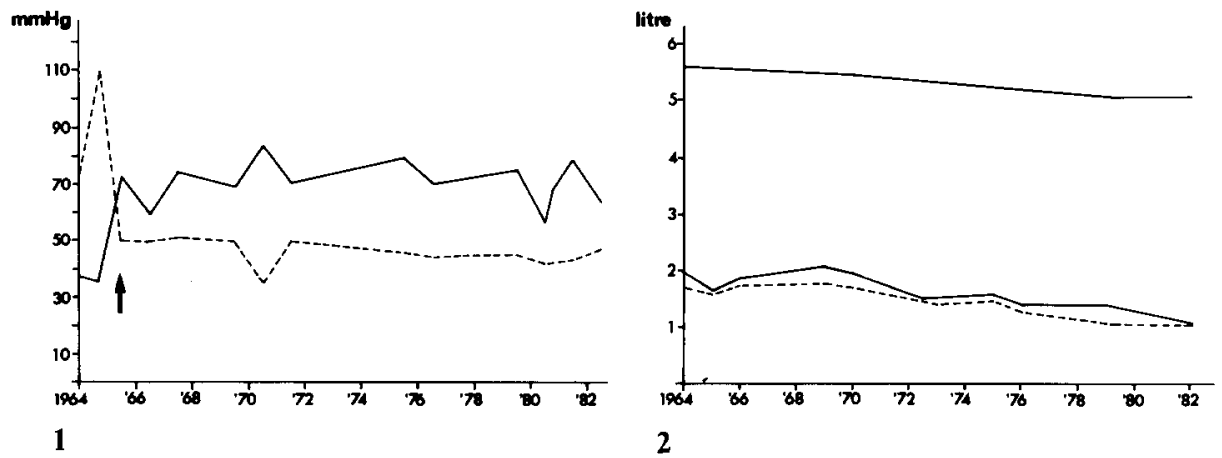

Fig. 1. Blood gas analysis of patient 1 during the years of treatment: continuous line, $\mathrm{PaO}_{2}$; dotted line, $\mathrm{PaCO}_{2}$; and arrow, start of intermittent cuirass respiration

Fig. 2. Course of pulmonary function of patient 1: continuous line, vital capacity (upper line predicted, lower shown by patient); dotted line, FEV 1 of the patient

Although by that time there was a significant reduction of his pulmonary functions, the further decrease over the years since then is in accordance with the normal decrease matched for age and height (Fig. 2). The other two patients show similar courses.

\section{Conclusion}

Diagnosis of the late-onset form of Pompe's disease is difficult. Initially, our patients were mistakenly diagnosed as having muscular dystrophy or polymyositis. Finally, a diagnosis of acid maltase deficiency was suspected on clinical grounds and confirmed by muscle biopsy. Major symptoms became evident in the third or fourth decade, but the disease probably started much earlier. Over a period of many years strength in pelvic, shoulder, and trunk muscles gradually decreased. Mild respiratory involvement developed, eventually leading to dyspnoea on exertion. Thereafter, severe respiratory insufficiency became manifest within a short time, necessitating intratracheal intubation and mechanical ventilation. When the acute disturbance had been overcome, the patients still needed some form of intermittent respiratory support to prevent chronic hypoventilation.

Respiratory support via a permanent tracheostomy has severe psychological and social consequences for the patient and should therefore be avoided whenever possible. Other forms of mechanical ventilation (oscillating bed [8], cuirass [7]) should be tried first. We used cuirass ventilators at first with commercially available shells. When this became inadequate because of leakage of air, tailormade shells were constructed. Since then our patients have had no more problems related to the mechanical ventilation. None was hospitalized again because of respiratory insufficiency. They have been treated in this way during 17, 7 and 4 years respectively and are in good condition. It is remarkable that, when the respiratory problems have been dealt with, the further loss of muscular power in these patients is very slow and more or less identical with the decline in the previous period. 
Acknowledgements. Many members of the medical, nursing and technical staff of our unit have participated over the years in the care of the patients. In particular, Sister O.T. Dallinga, R.N., should be mentioned, as she was responsible for the expert nursing care of these patients. Also we want to thank Mr. R. Drent for his patience, ingenuity and technical skill in constructing the tailor-made shells.

\section{References}

1. Arora NS, Rochester DF (1982) Respiratory muscle strength and maximal voluntary ventilation in undernourished patients. Am Rev Respir Dis 126:5-8

2. Busch HFM, Koster JF, van Weerden TW (1979) Infantile and adult-onset acid maltase deficiency occurring in the same family. Neurology (Minneap) 29:415-416

3. DiMauro S, Eastwood AB (1977) Disorders of glycogen and lipid metabolism. In: Griggs RC, Moxley RT (eds) Treatment of neuromuscular diseases (Advances in Neurology, no. 17). Raven Press, New York, pp 129-132

4. Engel AG, Gomez MR, Seybold ME, Lambert EH (1973) The spectrum and diagnosis of acid maltase deficiency. Neurology (Minneap) 23:95-105

5. Karpati G, Carpenter S, Eisen A, Aubé M, DiMauro S (1977) The adult form of acid maltase ( $\alpha$-1,4-glucosidase) deficiency. Ann Neurol 1:276-280

6. Loonen MCB (1979) The variability of Pompe's disease. Thesis, University of Rotterdam

7. O'Leary J, King R, Leblanc M, Moss R, Liebhaber M, Lewiston N (1979) Cuirass ventilation in childhood neuromuscular disease. $J$ Pediatr 94:419-421

8. Rosenow EC, Engel AG (1978) Acid maltase deficiency in adults presenting as respiratory failure. Am J Med 64:485-491

9. Sivak ED, Salanga VD, Wilbourn AJ, Mitsumoto H, Golish J (1981) Adult-onset acid maltase deficiency presenting as diaphragmatic paralysis. Ann Neurol 9:613-615

10. Wiers PWJ, Le Coultre R, Dallinga OT, van Dijl W, Meinesz AF, Sluiter HJ (1977) Cuirass respirator treatment of chronic respiratory failure in scoliotic patients. Thorax 32:221-228

Received March 25, 1983 